\title{
Calcium, actomyosin kinetics, myosin binding protein-c and hypertrophic cardiomyopathy
}

\author{
Gerry A Smith* \\ Department of Biochemistry, University of Cambridge, Tennis Court Rd. Cambridge, CB2 1QW, UK
}

\begin{abstract}
In an attempt to correct misunderstandings this article brings together the observations on Calcium, Myosin Binding Protein-C and Hypertrophic Cardiomyopathy in the basic function of cardiac muscle. A finding of many years ago is reiterated in a novel enzyme kinetic format with defined rate limiting step which makes CaATP the apparent substrate of the actomyosin cross-bridge. The relationship of these kinetics to recent observations on disruption of myosin binding protein-C is described along with how this bears on the understanding of the related cardiomyopathies.
\end{abstract}

\section{The roles of Calcium and Adenosine triphosphate (ATP)}

Based on our earlier publication [1], I have constructed simple derivation of the 'CaATP as cross-bridge substrate proposition' in terms of enzyme kinetics and present it here, For normal cardiac muscle the well-established accepted facts are, a) The myofilament ATPase dependency on $\mathrm{Ca}^{2+}$ shows cooperativity, i.e. a Hill coefficient of 2 indicating probable two site binding of activating $\mathrm{Ca}^{2+}$ [2-5]. b) The $\mathrm{Ca}^{2+}$ stimulated ATPase shows competitive inhibition by $\mathrm{Mg}^{2+}$ $[3,4]$. c) The primary binding site for $\mathrm{Ca}^{2+}$ activation is troponin which is measurable by ${ }^{45} \mathrm{Ca}^{2+}$ binding. This binding to troponin removes its blocking of the thin filament actin allowing the thick-filament myosin to form a cross-bridge to the actin [3-5]. d) The cross-bridge consumes ATP to generate contraction and/or tension in the muscle [6]. The ATP Hill coefficient of the ATPase is 1 i.e. unimolecular. e) The troponin binding site shows no affinity for $\mathrm{Mg}^{2+}$ so it is not the competitive $\mathrm{Mg}^{2+}$ inhibition site, this confirms the existence of a transient second $\mathrm{Ca}^{2+}$ binding site that is competitively inhibited by $\mathrm{Mg}^{2+}$, but not measurable by ${ }^{45} \mathrm{Ca}^{2+}$ binding, i.e. requires ATP.

f) The very simple conclusion is that in the unperturbed heart the cross-bridge is a $\mathrm{Ca}^{2+}$ ATPase and inhibited by $\mathrm{Mg}^{2+}$, i.e. MgATP binding to the myosin gives the relaxed state ready for $\mathrm{Mg}^{2+}-\mathrm{Ca}^{2+}$ exchange and cross-bridge cycling if the troponin is still $\mathrm{Ca}^{2+}$ bound. This is consistent with the $\mathrm{Ca}^{2+}$ cooperativity, i.e. Hill coefficient 2 . It is clear from two studies $[7,8]$, one very recent, that replacement of the product CaADP from the cross-bridge with MgATP is essential to complete the lever arm cycle.

There is one caveat to add to this scheme. For this kinetics to be true the replacement of $\mathrm{Mg}^{2+}$ with $\mathrm{Ca}^{2+}$ or a subsequent step dependent on this has to be the rate determining step. It is possible that the pyrophosphate bond is not hydrolyzed but a phosphate group is transferred to a protein (myosin light chain?), increasing the charge carried and thus raising the $\mathrm{Ca}^{2+}$ affinity of the ADP bound protein above that of $\mathrm{Mg}^{2+}$. This clearly happens with phosphorylation by myosin light chain kinase [9].

\section{Myosin binding protein-C (MyBP-C)}

Irving et al. [10] have shown that dissociation of MyBP-C from myosin by addition of its binding fragment $\mathrm{C} 1 \mathrm{mC} 2$ reduces the Hill coefficient for $\mathrm{Ca}^{2+}$ activation to unity and shifts the $\mathrm{Ca}^{2+}$ sensitivity to the affinity of troponin-C. This is also found by Hofmann et al. [11] on the reversible physical removal of the MyBP-C. The sole disruption of $\mathrm{C} 1 \mathrm{mC} 2$ is to the myosin binding of MyBP-C as is the reversible physical removal of it, leaving the $\mathrm{Ca}^{2+}$ troponin binding being the sole activator, i.e. $\mathrm{Ca}^{2+} \mathrm{Hill}$ Coefficient 1 . These procedures both remove the necessity of $\mathrm{Ca}^{2+}$ replacement of the $\mathrm{Mg}^{2+}$ that is bound with ATP to the myosin for cross-bridge cycling to occur, i.e. MgATP use becomes the rate limiting step. It is not known if the $\mathrm{Ca}^{2+}-\mathrm{Mg}^{2+}$ still occurs but probably not. The conclusion from this is that the function of myosin binding protein- $\mathrm{C}$ is to ensure that MgATP is not the apparent substrate for cross-bridge cycling in the unperturbed normal heart and the $\mathrm{Ca}^{2+}$ $\mathrm{Mg}^{2+}$ exchange defines the rate limiting step of the actomyosin ATPase. Thus, maintaining the full cooperativity of $\mathrm{Ca}^{2+}$ activation and normal $\mathrm{Ca}^{2+}$ sensitivity well below the Troponin affinity and hence full diastolic relaxation, see later. This is the first recorded biochemical function of MyBP-C although its phosphorylation is recognized as an important regulator in muscle function.

It has previously been accepted that MyBP-C is a key structural protein of the thick filament but being so easily reversibly removed [11] this is not so. It has an affinity for the thin filament, but this is displaced by the myosin.

\section{Hypertrophic cardiomyopathy}

Cardiomyopathy are diseases that to variable debilitating extent affects some 1 in 200 of the world's population. Hypertrophic cardiomyopathy, often undiagnosed as it appears as a healthy heartbeat in earlier stages, does eventually give problems with high diastolic and

${ }^{*}$ Correspondence to: Gerry A Smith, Department of Biochemistry University of Cambridge, Tennis Court Rd. Cambridge, CB2 1QW, UK, E-mail: gas1000@cam.ac.uk

Key words: calcium, actomyosin kinetics, myosin binding protein-C, hypertrophic cardiomyopathy

Received: October 10, 2019; Accepted: October 17, 2019; Published: October 28, 2019 
systolic pressure. What is more is one often hears of young people especially athletes and sportsmen experiencing sudden cardiac death as a result of the condition, when the conductance of their heart is extremely faulty resulting from the myofilament disarray of severe hypertrophy.

Hugh Watkins [12] and others [13,14] cite various mutations in genes encoding for sarcomeric proteins, mostly MyBP-C and myosin, that are a common cause of hypertrophic cardiomyopathy. This is as a result of muscle growth arising from incomplete relaxation between beats, i.e. sustained tension $[15,16]$, when the $\mathrm{Ca}^{2+}$ cooperativity is reduced and $\mathrm{Ca}^{2+}$ sensitivity greatly increased by mutated MyBP-C or myosin (MgATP reaction is then rate determining, as happens in vitro when disabling myosin MyBP-C binding to the myosin) $[10,11]$. The elastic giant protein titin binds myosin and MyBP-C. It has been proposed that sustained tension allows time for a degree of unfolding of the elastic portion of titin $[15,16]$ and the release of nuclear activating factors, e.g. muscle LIM protein, that are bound to the elastic region. The release of the activating factors promotes inappropriate growth of the sarcomere and the resulting disarray of muscle fibres observed in most cases of familial hypertrophic myopathy.

\section{Non-medication of hypertrophic cardiomyopathy}

For those that have hypertrophic myopathy diagnosed as a result of heart problems there is only lifestyle change recommended. A drug to increase relaxation rate is required to prevent further sustained tension mediated growth, levosimendan seems to do this but also increases the contraction rate and so would need to be used in conjunction with a $\mathrm{Ca}^{2+}$ uptake inhibitor to reduce the latter. It is interesting that this drug combination has been administered successfully when levosimendan has been used during rescue of an attempted suicide patient [17].

\section{Footnote}

Most of the above save the cardiac diseases, applies equally to mammalian skeletal muscle, with differences in isoforms of the constituent proteins.

\section{References}

1. Smith GA, Vandenberg JI, Freestone NS, Dixon HB (2001) The effect of Mg2+ on cardiac muscle function: is CaATP the substrate for priming myofibril cross-bridge formation and $\mathrm{Ca} 2+$ re-uptake by the sarcoplasmic reticulum. Biochem J 354: 539-551. [Crossref]
2. Chapman RA (1983) Control of cardiac contractility at the cellular level. Am J Physiol 245: 535-552. [Crossref]

3. Holroyde MJ, Robertson SP, Johnson JD, Solaro RJ, Potter JD (1980) The calcium and magnesium binding sites on cardiac troponin and their role in the regulation of myofibrillar adenosine triphosphatase. J Biol Chem 255: 11688-11693. [Crossref]

4. Pan BS, Solaro RJ (1987) Calcium-binding properties of troponin-C in detergent skinned heart muscle fibers. J Biol Chem 262: 7839-7849. [Crossref]

5. Morimoto S, Ohtsuki I (1994) Ca2+ binding to cardiac troponin-C in the myofilament lattice and its relation to myofibrillar ATPase activity. Eur J Biochem 226: 597-602. [Crossref]

6. Krause SM, Jacobus WE (1992) Specific enhancement of the cardiac myofibrillar ATPase by bound creatine kinase. J Biol Chem 267: 2480-2486. [Crossref]

7. Nicholl B, Blaikie C, Miller DJ, Stevenson O (2004) Can CaATP act as a substrate for cross-bridge activity in cardiac muscle. University of Glasgow. J Physiol 557: 19.

8. Ge J, Gargey A, Nesmelova IV, Nesmelov YE (2019) CaATP prolongs strong actomyosin binding and promotes futile myosin stroke. J Muscle Res Cell Motil. [Crossref]

9. Stelzer JE, Patel JR, Moss RL (2006) Acceleration of stretch activation in murine myocardium due to phosphorylation of myosin regulatory light chain. $J$ Gen Physiol 128: 261-272. [Crossref]

10. Kampourakis T, Yan Z, Gautel M, Sun YB, Irving M (2014) Myosin binding protein-C activates thin filaments and inhibits thick filaments in heart muscle cells. Proc Natl Acad Sci USA 111: 18763-18768. [Crossref]

11. Hofmann PA, Hartzell HC, Moss RL (1991) Alterations in Ca2+ sensitive tension due to partial extraction of C-protein from rat skinned cardiac myocytes and rabbit skeletal muscle fibers. J Gen Physiol 97: 1141-1163. [Crossref]

12. Flashman E, Redwood C, Moolman-Smook J, Watkins H (2004) Cardiac Myosin Binding Protein C, Its Role in Physiology and Disease. Circ Res 94: 1279-1289. [Crossref]

13. Wang L, Geist J, Grogan A, Hu LR, Kontrogianni-Konstantopoulos A (2019) Thick Filament Protein Network, Functions, and Disease Association. Compr Physiol 8: 631709. [Crossref]

14. Palmer BM (2005) Thick Filament Proteins and Performance in Human Heart Failure. Heart Fail Rev 10: 187-197. [Crossref]

15. Krüger M, Kötter S (2016) Titin, a Central Mediator for Hypertrophic Signaling, Exercise-Induced Mechano signalling and Skeletal Muscle Remodeling. Front Physiol 7: 76. [Crossref]

16. Boateng SY, Senyo SE, Qi L, Goldspink PH, Russell B (2009) Myocyte Remodelling in response to hypertrophic stimuli requires nucleocytoplasmic Shuttling of muscle LIM protein. J Mol Cell Cardiol 47: 426-435. [Crossref]

17. Sencan A, Adanır T, Terzi G, Atay A, Karahan N (2011) Treatment of calcium channel blocker overdose with levosimendan. Crit Care 15: 95. [Crossref]

Copyright: (C2019 Smith GA. This is an open-access article distributed under the terms of the Creative Commons Attribution License, which permits unrestricted use, distribution, and reproduction in any medium, provided the original author and source are credited. 